\title{
LANDMARKS IN MAPPING: 50 YEARS OF THE CARTOGRAPHIC JOURNAL
}

\author{
Edited by Kenneth Field and \\ Alexander J. Kent. \\ Maney Publishing, 2014. \\ 416 pages, maps, diagrams. $\$ 125.00$, \\ hardcover. \\ ISBN: 978-1-909662-38-4 \\ Review by: Judith A. Tyner, California State University, \\ Long Beach
}

In 1975, John Wolter referred to the "emerging discipline of cartography" that began after WWII (Wolter 1975). At that time, cartography was beginning to be viewed not as a mere tool for geographers, but a branch of knowledge in its own right. Whereas, in earlier days, the only cartography-related articles to be found in journals (or acceptable for thesis or dissertation subjects) concerned map projections or historical subjects, cartographers were beginning to analyze how maps work, and cartography textbooks discussed not just how to, but why. Arthur Robinson wrote the first dissertation on a cartographic subject, Foundations of Cartographic Methodology, which was published in 1952 as The Look of Maps.

Wolter also noted the post-war proliferation of organizations and journals devoted to cartography. The American Congress on Surveying and Mapping was founded in 1941 with a journal, Surveying and Mapping; the British Cartographic Society began in 1964 and launched Cartography, now The Cartographic Journal; The Canadian Cartographer, now Cartographica, was also founded in 1964. Articles in these journals dealt with automation, how maps communicate, symbolization, perception, and the like. Now, more than 50 years later, cartographers are looking back at the early days of the discipline; several books have been published that examine classic and groundbreaking articles in the field, including The Map Reader, which covers the field in general, Classics in Cartography, which looks at landmark articles in Cartographica, and this work, Landmarks in Mapping, celebrating the $50^{\text {th }}$ anniversary of The Cartographic Journal.
Landmarks consists of a brief introduction that describes the history of the British Cartographic Society and its journal, plus the rationale for article selection. It is followed by sixteen articles regarded as landmarks in the field. The chosen articles are presented in chronological order, from the earliest from 1965 to the most recent at the time of writing, 2012. "Reflections" on the articles written by members of the Editorial Board follow each selection. The reflections do not all follow exactly the same structure, although each is about 2-3 pages, has a discussion of the article and explains why the reviewer considers it important. Each has a list of references. These reflections are interesting, in part, in that they reveal not just the trends of the field, but the current thinking in the cartographic community and what scholars and practitioners now consider relevant.

For the editors of this type of book, the biggest difficulty lies in which articles should be considered classic. The editors of Landmarks in Mapping state that their intention "is to bring a flavour of the quality and breadth of the Journal into one volume that spans its history" (4). Various models for inclusion of papers were tried based on different rationales, such as the number of citations, the number of downloads, and personal experience. A further attempt was to choose from winners of the Henry Johns Award of the BCS (first awarded in 1975), or papers that, while not necessarily considered landmarks in their time, were deemed critical to the development of the field or those that were deemed worthy by the members of the Editorial Board. The final selection was based largely on the opinions of the reviewers, who are all members of the Editorial Board: "...papers only made the final cut if, in light of the above criteria, the reviewer made a solid justification for its inclusion" (4).

Of course, each reader of the book will have their own idea of the appropriateness of the sixteen selections, but the articles range from Waldo Tobler's 1965 article "Automation in the Preparation of Thematic Mapping" to Damien Demaj and Kenneth Field's 2012 "Reasserting Design Relevance in Cartography.” I will not comment on my preferences for inclusion or omission, save to note that there is a skewing toward papers published in the $21^{\text {st }}$ 
century. For the 35 year period from 1965 to 2000, there are 8 papers, and 4 of those are from 1990; the 12 year period from 2001 to 2012 also has 8 papers, 3 from 2008 alone. Were there only 4 landmark articles in the 25 years from 1965 to 1990 ? I wonder if 35 years from now the 8 papers from 2003 to 2012 will still be considered landmark works.

Of course, with sixteen reviewers there will be variations, but I might note that, in some cases, the reviewers do not put themselves in the context of the time the article was written, and do not discuss its contemporary significance. Nor do we learn why it was considered important and worthy of publication in the Journal or why the three award-winning papers were given the Henry Johns Award.

The Cartographic Journal is credited as the first general-distribution journal of cartography to appear in English. This should be clarified. The American Congress on Surveying and Mapping was founded in 1941 and the Cartography Division was formed in 1950. As noted above, ACSM published Surveying and Mapping, which dealt with cartographic subjects as well as surveying; The American Cartographer, which was "purely" cartographic, was split off in 1975 and it is probably this date that the editors consider.

Two things I would have liked to see, but which probably were omitted due to editorial and publishing constraints, were brief biographies of the article authors and reviewers, and an index. For those new to the field, it would be helpful to know who the article authors were and their overall contributions to the field. As it is, the reader is not even told what the author's affiliation was. In some cases this is dealt with in the "Reflections," such as Kenneth Field's comments on Waldo Tobler's "Automation in the Preparation of Thematic Maps.” The reviewers are simply listed by name and University or professional affiliation. Again, those who have been in the field for some time will probably know of these Editorial Board members, but for those new to the field or graduate students who may be using the book in a seminar, the information would be helpful. Likewise, an index would also have been useful. This is admittedly a large task, but would aid a reader who is looking for a particular topic or subtopic.

These small complaints aside, I definitely recommend this book. It is a valuable addition to the history of cartography in the past 50 years, giving, as the editors desired, the "flavor" of the period, and also serves as a starting point for researchers in cartography. It will be a much used resource for those in seminars of mapping sciences.

\section{REFERENCE}

Wolter, John. 1975. "The Emerging Discipline of

Cartography.” PhD diss., University of Minnesota.

\section{MARYLAND GEOGRAPHY: AN INTRODUCTION}

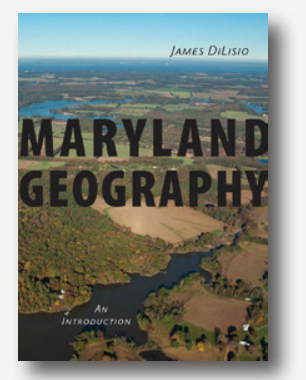

By James Dilisio.

Johns Hopkins University Press, 2014.

320 pages, 43 line drawings. $\$ 35.00$, softcover.

ISBN: 978-1-4214-1482-9

Review by: James Saku, Frostburg State University

Professor James DiLisio is an accomplished academician and administrator at Towson University. During his 35-year teaching career, he has taught several geography courses, including Geography of Maryland. He published his first book on the state of Maryland in the 1980s. That book undoubtedly served the needs of students and professors of Maryland geography for several years. However, with socio-economic changes in the state over the past three decades, DiLisio recognized the need for updating and publishing a new textbook. This new book, Maryland Geography: An Introduction, is comprehensive and covers a variety of topics including physical, economic, political, and social geography. Overall, it offers an excellent understanding of the regional geographic landscape of Maryland. 